\title{
PARTICIPAÇÃO EM UMA COMUNIDADE VIRTUAL DE PRÁTICA DESENHADA COMO MEIO DE DIMINUIR A LACUNA PESQUISA-PRÁTICA NA EDUCAÇÃO EM BIOLOGIA
}

\section{Participation in a virtual community of practice designed as a way of bridging the research-practice gap in biological education}

\author{
Charbel Niño El-Hani ${ }^{1}$ \\ Ileana María Greca
}

\begin{abstract}
Resumo: Este trabalho apresenta resultados relativos à participação numa comunidade virtual de prática (ComPratica) desenhada como ferramenta para diminuir a lacuna pesquisa-prática na educação em biologia. A ComPratica reúne professores do Ensino Médio, licenciandos, pesquisadores e estudantes (graduação e pós-graduação), e inclui fóruns e chats sobre assuntos relacionados ao ensino de biologia. Uma atividade central na comunidade é a construção de pesquisa colaborativa, situada nas condições reais das salas de aula, envolvendo professores e pesquisadores em equipes não hierarquizadas. $O$ sucesso inicial da comunidade é indicado pelo alto nível de participação, envolvendo $25 \%$ dos membros; pela diversidade de atividades e temas em seu interior; e pelo desenvolvimento de 8 projetos de pesquisa focados, sobretudo, em questões levantadas pelos professores. Neste artigo, apresentamos a ComPratica, discutimos dados relativos à participação dos membros, às visões dos professores sobre a comunidade, e relatamos achados de uma análise temática das mensagens enviadas em seus fóruns.
\end{abstract}

Palavras-chave: Comunidade de prática. Desenvolvimento profissional. Lacuna pesquisa-prática. Formação de professores.

\begin{abstract}
This paper reports results related to the participation in a virtual community of practice (ComPratica) designed as a tool for bridging the research-practice gap. ComPratica gathers in-service high school teachers, preservice teachers, researchers, and graduate and undergraduate students, and include forums and chats about matters related to biological education. A central activity in the community is the construction of collaborative research, situated in real classroom conditions, involving teachers and researchers in non hierarchical teams. The initial success of the community is indicated by the high degree of participation, involving $25 \%$ of the members; the diversity of activities and themes within it; and the development of 8 research projects mostly focused on issues raised by the teachers. In this paper, we describe ComPratica and discuss data concerning the members' participation, the teachers' views about the community, and report findings of a thematic analysis of the messages sent in its forums.
\end{abstract}

Keywords: Community of practice. Professional development. Research-practice gap. Teacher education.

${ }^{1}$ Graduado em Ciências Biológicas, doutor em Educação. Professor Associado 1, Instituto de Biologia, Universidade Federal da Bahia, Salvador, BA, Brasil. charbel.elhani@pesquisador.cnpq.br

${ }^{2}$ Graduada em Profesorado En Matemática, Física y Cosmografía, doutora em Física. Professora, Escola Politécnica Superior, Departamento de Física, Universidade de Burgos, Burgos, Espanha. <ilegreca@hotmail.com>

${ }^{1}$ Rua Barão de Jeremoabo, s/n

Ondina - Salvador, BA

40.170-115 


\section{A lacuna pesquisa-prática}

Uma lacuna entre pesquisa e prática tem sido geralmente reconhecida pelos pesquisadores em educação e pelos professores, tanto na educação em termos gerais, quanto no ensino de ciências (e.g., PEKAREK; KROCKOVER; SHEPARDSON, 1996; KENNEDY, 1997; LÜDKE, 2001; MCINTYRE, 2005; MIRETZKY, 2007; SCHOONMAKER, 2007; PENA; RIBEIRO FILHO, 2008; BROEKKAMP; VAN HOUT-WOLTERS, 2007; VANDERLINDE; VAN BRA$A K, 2010)$. Esta lacuna diz respeito à percepção de que professores não usam, com frequência, resultados da pesquisa educacional para construírem e refletirem sobre sua prática, assim como muitas vezes não dão grande valor à contribuição da pesquisa acadêmica para o trabalho em sala de aula. $\mathrm{O}$ mesmo tem sido observado em relação aos tomadores de decisão no campo educacional. Além disso, mudanças nas práticas escolares não resultam tipicamente da pesquisa acadêmica, mas de outras fontes, como políticas governamentais, materiais curriculares, livros didáticos, nas quais os resultados da pesquisa desempenham, quando o fazem, um papel indireto.

A lacuna pesquisa-prática não é um problema apenas do campo educacional. Em muitas áreas do conhecimento, a mesma questão tem sido colocada, a exemplo da ecologia (ALLEN; HOEKSTRA, 1992), medicina (BERO et al., 1998), gestão e desenvolvimento de recursos humanos (SHORT, 2006), pesquisa sobre desastres naturais (MYERS, 1993). Este é, pois, um problema que deve ter causas mais gerais do que alguma deficiência específica do campo educacional. Ele parece ser, antes, uma característica genérica da relação entre pesquisa acadêmica e prática profissional, e esta generalidade, por sua vez, sugere que aspectos estruturais do trabalho científico e/ou da prática estão envolvidos. Nesta direção, a lacuna pesquisa-prática pode ser vista como uma consequência da forma como a pesquisa educacional tem sido conduzida, organizada e/ou disseminada (KENNEDY, 1997); ou como uma decorrência de dificuldades de se colocar em relação duas classes diferentes de conhecimentos (MCINTYRE, 2005). Aqui, enfocaremos, sobretudo, esta segunda possível razão para a lacuna pesquisa-prática.

As origens da lacuna pesquisa-prática podem não residir numa série de fatores que são frequentemente mencionados quando se discute o problema, tais como: a natureza do sistema escolar, a autoindulgência e irresponsabilidade dos pesquisadores, a complacência e os interesses pessoais dos professores, ou abordagens anti-intelectuais ou pouco profissionais nas práticas pedagógicas. É plausível pensar que o problema esteja fundado em razões mais profundas do que estas, por exemplo, de caráter epistemológico. A lacuna pesquisa-prática pode ser pensada, com proveito, como um problema de como se relacionar dois tipos de conhecimento muito diferentes, que residem em extremos opostos de um espectro de conhecimentos relacionados ao ensino e à aprendizagem (HARGREAVES, 1999; MCINTYRE, 2005). O trabalho cotidiano dos professores requer um conhecimento pedagógico específico para cada contexto, que informe diretamente suas práticas em face das características únicas de cada turma, assunto e lição. Este é, em parte (ainda que não exclusivamente, como mostram os professores reflexivos), um conhecimento de "como" fazer, sendo muito diferente do conhecimento "de que", i.e., do conhecimento proposicional produzido pela pesquisa (MCINTYRE, 2005). Para que a pesquisa acadêmica contribua para práticas situadas de ensino, esta contribuição deve ter lugar a partir da construção de relações com o conhecimento pedagógico dos docentes.

Contudo, o conhecimento baseado na pesquisa, por sua natureza mais geral e proposicional, não pode ser diretamente traduzido no conhecimento situado e particular de como lidar com salas de aula, assuntos, lições. Tentativas de se encontrarem atalhos fáceis neste 
processo de tradução entre conhecimentos tão distintos podem ser prejudiciais, sobretudo, se o conhecimento docente não for levado em consideração. Para enfrentar o problema da lacuna pesquisa-prática, necessitamos, então, de um duplo movimento (que, ao fim e ao cabo, se constitui na construção de um diálogo entre pesquisadores e professores): do conhecimento produzido pela pesquisa rumo à particularidade da sala de aula, por meio do desenvolvimento e da implementação de propostas para a prática pedagógica, e do conhecimento pessoal dos professores rumo a um maior grau de generalidade e, portanto, a uma maior facilidade de ajuste a novas situações, a partir da reflexão docente, bem como da construção de uma pesquisa feita pelos professores. Estes movimentos se tornarão mais fáceis se professores e pesquisadores estiverem reunidos em equipes verdadeiramente colaborativas. Se trabalharmos com os docentes em comunidades nas quais atuemos, pesquisadores e professores, como pares, poderemos ter melhores condições de tornar o conhecimento baseado na pesquisa acessível aos professores e, ao mesmo tempo, desafiar crenças dos membros de tal comunidade (sejam professores ou pesquisadores) que possam tornar certos achados e ideias sobre o ensino e a aprendizagem inacessíveis ou contraintuitivos. Desta maneira, podemos ser capazes de encontrar caminhos para integrar proposições baseadas na pesquisa nos esquemas pessoais que os professores usam para reconhecer turmas, estudantes e situações como similares a outras que experimentaram anteriormente, e, portanto, para escolher como agir com base em um repertório de ações possíveis que construíram ao longo de suas carreiras. Além disso, se os resultados da pesquisa se tornarem conceitualmente acessíveis aos professores, eles poderão contribuir para o pensamento reflexivo dos docentes acerca de sua abordagem pessoal do processo educativo. Por fim, a própria pesquisa educacional será transformada, tornando-se mais autêntica e relevante, se realizada em equipes colaborativas de professores e pesquisadores.

Em nossa visão, a lacuna pesquisa-prática deve ser uma preocupação prioritária para todos os pesquisadores da área de ensino de ciências. Se o que aprendemos por meio da pesquisa sobre a educação científica não tiver qualquer efeito ou não mais do que um efeito desprezível sobre a própria realidade que investigamos, corremos o risco de fazer um trabalho espúrio. Devemos, pois, buscar caminhos para diminuir a lacuna pesquisa-prática. Em nosso entendimento, estes caminhos passam, necessariamente, pelo professor, como ponto-chave do processo de ensino e aprendizagem. É importante investigar uma variedade de ferramentas que possam criar condições para uma aproximação entre o conhecimento oriundo da pesquisa e o conhecimento pedagógico dos professores. Em nossas iniciativas, temos trabalhado com duas abordagens: de um lado, a construção de uma comunidade virtual de prática, envolvendo professores e pesquisadores; de outro - mas não em separado da primeira abordagem -, a construção de pesquisa colaborativa em equipes não hierarquizadas de professores e pesquisadores. Neste artigo, apresentamos resultados relativos à primeira abordagem, a construção de uma comunidade virtual de prática (WENGER, 1998), denominada ComPratica ${ }^{3}$, com a característica colaborativa mencionada acima.

\footnotetext{
${ }^{3}$ A ComPratica pode ser visitada no seguinte endereço: http://www.moodle.ufba.br/course/view.php?id=8823. Visitantes não podem postar na comunidade, mas podem ter acesso aos conteúdos das discussões travadas na mesma. Professores de biologia do Ensino Médio de qualquer estado brasileiro interessados em participar da comunidade podem escrever para o prof. Charbel El-Hani (IB-UFBA; <charbel.elhani@pq.cnpq.br>)
} 


\section{Comunidades de prática como uma maneira de diminuir a lacuna pesquisa-prática}

Uma comunidade de prática (CoP) é concebida por Lave e Wenger (1991) como um grupo de indivíduos com distintos conhecimentos, habilidades e experiências, que participam de modo ativo em processos de colaboração, compartilhando conhecimentos, interesses, recursos, perspectivas, atividades e, sobretudo, práticas, para a construção de conhecimento tanto pessoal quanto coletivo. Uma CoP, quando efetivamente funciona, gera e se apropria de um repertório compartilhado de ideias, objetivos e memórias; desenvolve recursos, como ferramentas, documentos, rotinas, vocabulários e símbolos, que, em certa medida, carregam consigo o conhecimento acumulado pela comunidade. Em outras palavras, uma comunidade de prática envolve praxis: maneiras compartilhadas de fazer e de se aproximar das coisas de que se ocupam as pessoas que a integram. Portanto, CoPs envolvem a ideia de Schön (1983) de raciocínio sobre a ação (reasoning on action). Por isso, embora construídas como grupos ou projetos de grupos, as CoPs são grupos com características específicas, sendo uma das mais notáveis o próprio senso de comunidade, na qual todos os membros investem e contribuem, com valores e projetos compartilhados (WISKER; ROBINSON; SHACHAM, 2007).

O conceito de CoP implica uma visão da aprendizagem como processo social, e não individual. Desta perspectiva, para aprender, é necessário participar, envolvendo-se ativamente em processos sociais, construindo e reconstruindo uma identidade de pertencimento à CoP, ressituando (e não simplesmente traduzindo ou transpondo) o significado das descrições e prescrições formais - válidas sempre e em todo lugar e, portanto, sem validade em nenhum âmbito em particular (TOULMIN, 2001) - para a efetiva realização de uma tarefa. Se entendida nestes termos, a aprendizagem está sempre situada dentro de alguma CoP.

As características das CoPs e o modo como seus membros trabalham e se relacionam estão documentados em pesquisas sociológicas e antropológicas (WENGER, 1998; BROWN; DUGUID, 2000; LAVE; WENGER, 1991; BARAB; DUFFY, 2000). Embora estas comunidades tenham sido detectadas em muitos âmbitos profissionais, elas raramente são encontradas entre os profissionais da educação (SCHLAGER; FUSCO, 2004). Com os professores usualmente isolados na sua sala de aula, fechados à reflexão sobre sua prática, em decorrência de uma série de fatores que têm estruturado o trabalho docente - como a carga horária excessiva, as dificuldades de transição da formação para a prática etc. - a tarefa docente tende a constituir uma atividade solitária e poucas têm sido as oportunidades para os docentes aprimorarem seu desenvolvimento profissional. Em teoria, esta situação pode ser superada por meio de CoPs, como ambientes em que os professores podem refletir sobre conteúdos específicos, práticas didáticas, necessidades de formação etc., colocar suas próprias dúvidas e oferecer sugestões a outros pares, e, dessa maneira, reinventar coletivamente sua prática (DALGARNO; COLGAN, 2007). Assim, elas têm sido vistas como ferramentas adequadas para o desenvolvimento profissional dos professores, com algumas aplicações neste sentido tendo aparecido nos últimos anos, como: a comunidade de professores destinada a ajudar licenciados a obterem certificação acadêmica, descrita por Barab, Barnett e Squire (2002); a comunidade de prática em rede Tapped In (SCHLAGER; FUSCO; SCHANK, 2002), ou a Connect-Me, uma comunidade virtual de prática para professores de matemática (DALGARNO; COLGAN, 2007). A implementação de CoPs de professores pode ser, inclusive, muito importante 
para a melhoria da educação, na medida em que a existência de comunidades de professores tem sido considerada uma variável crítica para o sucesso de inovações e reformas educacionais, e CoPs têm sido propostas como catalisadores poderosos para o aprimoramento das práticas docentes (LIEBERMAN, 1996; RÉNYI, 1996).

É relevante investigar, então, se CoPs podem contribuir para diminuir a lacuna pesquisa-prática. Uma CoP envolvendo professores e pesquisadores pode, em princípio, criar condições para um duplo movimento, da pesquisa para a prática e da prática para a pesquisa, por meio da participação de seus membros em relações de engajamento mútuo. Este engajamento pode culminar, por sua vez, na construção de projetos realizados de maneira colaborativa e situada, com a participação de professores em todas as suas etapas, no contexto concreto das salas de aula. Projetos colaborativos de pesquisa com esta natureza são, para vários autores, um elemento-chave para a diminuição da lacuna pesquisa-prática (HARGREAVES, 1999; MCINTYRE, 2005; BROWN, 2005). Surge daí a ideia de vincular uma CoP de professores e pesquisadores à construção de tais projetos. Desse modo, uma dinâmica que leve à diminuição da lacuna pesquisa-prática pode ser fomentada no contexto do contínuo de tipos de conhecimento sobre o ensino e a aprendizagem proposto por McIntyre (2005), que inclui: conhecimento pedagógico prático dos docentes; articulação do conhecimento prático; pensamento reflexivo ou deliberativo para o ensino em sala de aula; pesquisa situada na sala de aula; conhecimento gerado por escolas e redes escolares voltadas para a pesquisa (HARGREAVES, 1999); sugestões práticas para o ensino baseadas na pesquisa; revisões de pesquisa sobre temas particulares; achados e conclusões da pesquisa educacional. Esta dinâmica envolve, de um lado, o movimento de professores do conhecimento prático para a incorporação de conhecimento baseado na pesquisa, por intermédio da articulação de suas práticas e do pensamento reflexivo a seu respeito, seguida pelo engajamento em pesquisa situada em suas salas de aula; de outro, o movimento de pesquisadores rumo à produção de sugestões claras e úteis para práticas de ensino a partir de sua pesquisa, de revisões de pesquisas sobre temas determinados, até a construção conjunta de processos de pesquisa com os professores como pares, em suas salas de aula, sempre levando em conta os conhecimentos, as preocupações, as identidades, as práticas dos professores.

A CoP enfocada neste trabalho emergiu a partir de uma ideia proposta por Greca e González (2002), a saber, de que é necessário reunir, em CoPs, pesquisadores da área de ensino de ciências, pesquisadores especialistas nas áreas de conteúdos específicos, estudantes e professores de ciências, para se conseguir um aprimoramento efetivo da educação científica. Os resultados de uma implementação-piloto da proposta original, desenvolvida em $2004 \mathrm{com}$ docentes espanhóis que ensinam ciências no nível Fundamental (GARCÍA GANDÍA et al., 2005), levaram à conclusão de que também era preciso incluir, nessas comunidades, pósgraduandos da área de ensino de ciências e estudantes de licenciaturas, de modo a gerar comunidades sustentáveis ao longo do tempo.

Dada a potencialidade das CoPs como meios de diminuir a lacuna pesquisa-prática, é relevante investigar em que medida podem se constituir CoPs na área de ensino de ciências e, caso possam de fato se estabelecer, como elas podem diminuir a lacuna pesquisa-prática e, desta forma, ajudar no desenvolvimento profissional docente. Esta foi a motivação inicial para a implementação, dentro da área de biologia, de um ambiente virtual que pretendíamos que se constituísse como uma CoP, como descrito na seção seguinte. Resultados que permitem afir- 
mar que a ComPratica tem, de fato, funcionado como uma CoP são relatados em El-Hani e Greca (2010). Neste trabalho, em particular, discutimos resultados concernentes à participação dos membros nesta $\mathrm{CoP}$ e às visões dos professores participantes sobre a mesma, assim como relatamos achados de uma análise temática das mensagens enviadas em seus fóruns.

\section{Metodologia}

\section{Descrição geral da ComPratica}

A ComPratica é uma CoP reunindo pesquisadores, pós-graduandos e graduandos ligados a um grupo de pesquisa ${ }^{4}$ e professores de biologia em serviço e em formação inicial. Dado o pouco tempo de que dispõem os professores, optamos por uma CoP, sobretudo, virtual, embora reuniões presenciais com todos ou parte dos membros sejam possíveis e estejam sendo, de fato, realizadas, com a freqüência de uma reunião por semestre. Para implementá-la, foi necessário um ambiente cooperativo de aprendizagem, capaz de promover comunicação multidirecional (assíncrona, por meio de fóruns, principal meio de comunicação na comunidade, e síncrona, por intermédio de chats, necessários para discutir, mais intensa e colaborativamente, determinado tópico), permitir a autoria colaborativa e registrar os conteúdos produzidos pelo grupo. Com base nestas características, escolhemos o sistema de gerenciamento de cursos Moodle ${ }^{\mathrm{TM}}$ (http://moodle.org) como plataforma para construir a ComPratica. Este é um sistema aberto (software livre) largamente usado, instalado na UFBA há mais de seis anos (contando com uma equipe de suporte bem preparada para ajudar aos professores e pesquisadores que o utilizam), inteiramente em português, facilmente configurado pelos usuários e, como é implementado em PHP, não possui requisitos de sistema operacional que não possam ser satisfeitos pelos computadores disponíveis para os professores, seja nas escolas, seja em suas casas. Ele também não necessita de conexões rápidas de internet para ser usado de modo adequado. Nos três anos em que temos usado o Moodle ${ }^{\mathrm{TM}}$ como plataforma para a ComPratica, ele tem suprido de maneira satisfatória as necessidades colocadas pela CoP, apenas com pequenos problemas na operação dos chats, por vezes instáveis.

A comunidade está focada no ensino de biologia, no nível médio de escolaridade. Sua organização incluía inicialmente cinco fóruns: (1) fórum de notícias; (2) fórum sobre ensino de ecologia; (3) fórum sobre ensino de genética e biologia celular \& molecular; (4) fórum sobre didática das ciências, abordando questões de caráter mais geral, relacionadas à educação científica. Esta divisão temática foi proposta com a intenção de focar a comunidade naqueles tópicos em que era mais provável uma colaboração produtiva entre os professores e os pesquisadores do grupo. Os professores foram informados, contudo, de que novos fóruns poderiam ser propostos, algo que, de fato, ocorreu, com a abertura de um fórum sobre o ensino de botânica, cujas mensagens não serão analisadas no presente artigo, por ele ser ainda recente.

${ }^{4}$ Grupo de Pesquisa em História, Filosofia e Ensino de Ciências Biológicas, coordenado pelo prof. Charbel N. El-Hani no Instituto de Biologia,UFBA. 
A ComPratica também foi planejada para promover a construção de projetos de pesquisa situados em sala de aula e de curto termo. Para alcançar este objetivo, questões e ideias colocadas durante as discussões, especialmente pelos professores, têm sido aproveitadas para que sejam feitas propostas de desenvolvimento de estratégias de ensino, materiais instrucionais e outros recursos, coconstruídos com os professores, e que possam conduzir a investigações situadas em suas salas de aula.

Tendo em vista que era plausível que a participação na comunidade levasse a inovações pedagógicas, consideramos importante incorporar medidas que pudessem empoderar os professores para enfrentarem possíveis resistências de seus pares, da administração escolar, e até mesmo de estudantes e pais, diante de tais inovações (ver, p. ex., MIRETZKY, 2007). Por isso, foi pedido a eles que tentassem envolver na CoP mais professores de sua escola, dado que, em equipe, pudessem fazer frente a tal resistência com maior facilidade do que se estivessem isolados. Adotamos, contudo, uma postura flexível diante de professores que não conseguiram engajar colegas na iniciativa. Nestes casos, eles entraram sozinhos na comunidade, e ficamos atentos a possíveis problemas que enfrentassem em seus ambientes escolares.

\section{Coleta e análise dos dados}

A investigação foi realizada de modo qualitativo, constituindo um estudo de caso sobre o uso de CoPs no ensino de ciências como ferramentas para diminuir a lacuna pesquisaprática.

Relatórios foram obtidos para cada participante por meio de ferramenta do próprio Moodle ${ }^{\mathrm{TM}}$, em 10/04/2009, permitindo coletar informações sobre as datas de inscrição e as ações dos membros da CoP. Com estes dados, foi possível produzir um retrato da dinâmica da comunidade, mostrando o aumento do número de participantes ao longo dos meses e a distribuição da participação nas várias atividades da ComPratica entre seus membros. Nós também identificamos quais participantes iniciaram fios (threads) de discussão em todos os fóruns da comunidade, considerando apenas fios que incluíssem mais de uma mensagem. Também obtivemos, no sistema Moodle ${ }^{\mathrm{TM}}$, relatórios para cada um dos fóruns e chats incluídos na ComPratica, o que permitiu verificar a distribuição da participação e das mensagens entre eles.

Para estudar quais são os temas que têm gerado a participação dos membros, foi criado um banco de dados com todas as mensagens enviadas até o final de abril de 2009. A categorização das mensagens enviadas nos fóruns permitiu verificar os assuntos que geraram participação na comunidade. As categorias emergiram por um processo indutivo, ao longo da análise das mensagens. A maioria das mensagens pôde ser classificada numa única categoria, mas houve alguma superposição de categorias. A análise não incluiu o fórum de notícias. A categorização dos conteúdos das mensagens foi realizada por dois pesquisadores de forma independente, sendo utilizada, contudo, uma categorização consensual, obtida a partir da discussão de divergências na categorização. A confiabilidade e a validade interna do estudo (KIRK; MILLER, 1986) foram aumentadas por meio da apreciação crítica mútua das coletas e análises de dados realizados por cada autor. No Quadro 1, aparecem as categorias encontradas, exemplificadas com trechos das mensagens dos participantes. 
El-Hani C. N.; Greca, I. M.

Quadro 1. Categorias dos temas abordados nos fóruns da ComPratica até 29/04/2009.

\begin{tabular}{|c|c|c|}
\hline Categoria & Descrição & Exemplos \\
\hline $\begin{array}{l}\text { Desafios do ensino de } \\
\text { biologia no nível médio }\end{array}$ & $\begin{array}{l}\text { Nesta categoria, foram } \\
\text { incluídas mensagens } \\
\text { que discutiam } \\
\text { dificuldades enfrentadas } \\
\text { pelos professores de } \\
\text { biologia nas salas de } \\
\text { aula do Ensino Médio. } \\
\text { Estas dificuldades foram } \\
\text { abordadas tanto em } \\
\text { termos gerais quanto } \\
\text { específicos. Neste } \\
\text { último caso, a discussão } \\
\text { podia ser tanto de certo } \\
\text { nível de generalidade, } \\
\text { por exemplo, sobre } \\
\text { ensino de evolução, } \\
\text { quanto de conceitos } \\
\text { particulares, tal como o } \\
\text { de nicho ecológico. }\end{array}$ & $\begin{array}{l}\text { Alguns graduandos que partem para conhecer o dia a dia da } \\
\text { estrutura escolar, a partir da modalidade de estágio, percebem o } \\
\text { quanto a sala de aula está carente de motivação. Competimos } \\
\text { com internet, celular, casas de jogos... e nossos temas } \\
\text { científicos (claro com transposição didática) não são tão aceitos } \\
\text { pelos estudantes. Uma das formas de tentar mudar essa } \\
\text { realidade é fazer com que os docentes da instituição trabalhem } \\
\text { de forma conjunta, trazer temas do cotidiano (atuais que são até } \\
\text { mesmo vinculados na mídia) que possam ser confrontados com } \\
\text { os nossos conteúdos biológicos, trabalhar com projetos, feira de } \\
\text { ciências, aulas experimentais... isso pode ser um caminho... (SN, } \\
26 / 04 / 2008)^{5} \text {. } \\
\text { Este ano estou trabalhando o tema evolução com meus alunos. } \\
\text { É sempre muito difícil trabalhar esse tema visto que grande parte } \\
\text { dos alunos traz consigo dogmas religiosos. Muitos deles me } \\
\text { perguntam, quando acabamos as discussões, se eu realmente } \\
\text { acredito na evolução (- Pró, a Senhora realmente acredita nisso? } \\
\text { A Bíblia diz...). Parto sempre do princípio de que a ciência se } \\
\text { baseia em fatos prováveis e não no sobrenatural e digo a eles } \\
\text { que minhas aulas têm por base a ciência, e que não } \\
\text { discutiremos aspectos religiosos (não posso ferir as ideologias } \\
\text { de cada um deles. Acredito que não cabe a mim isso). Não sei } \\
\text { se essa é a maneira correta e aceito sugestões para contornar } \\
\text { esse problema (AcS, 06/03/2008). }\end{array}$ \\
\hline Temas educacionais & $\begin{array}{l}\text { Nesta categoria, } \\
\text { incluímos mensagens } \\
\text { sobre uma variedade de } \\
\text { assuntos relativos à } \\
\text { educação. }\end{array}$ & $\begin{array}{l}\text { Realmente os livros didáticos não nos dão subsídios para } \\
\text { desenvolver essa abordagem histórico-filosófica da ciência que } \\
\text { tanto desejamos. A nossa formação também deixa MUITO a } \\
\text { desejar nesse assunto. Vou dizer que eu não tive sequer uma } \\
\text { disciplina, durante toda a minha graduação, que tentasse dar } \\
\text { esse olhar sobre as ciências... MI, eu concordo com você que } \\
\text { será um trabalho para muitos e por muito tempo. Mas o que mais } \\
\text { me angustia é que eu não vejo esse trabalho começar... Eu falo, } \\
\text { mas me incluo no grupo de pessoas que está a espera de } \\
\text { alguém. Quem sabe essa não é a oportunidade para } \\
\text { começarmos a produção de textos deste tipo... (LC, 27/02/2009). }\end{array}$ \\
\hline $\begin{array}{l}\text { Questões conceituais } \\
\text { relativas ao } \\
\text { conhecimento biológico }\end{array}$ & $\begin{array}{l}\text { Esta categoria inclui } \\
\text { mensagens sobre } \\
\text { aspectos conceituais }\end{array}$ & $\begin{array}{l}\text {... o que explica isso é a defesa de François Jacob de que o } \\
\text { processo de evolução deveria ser descrito através da metáfora } \\
\text { com o trabalho de funilaria, em lugar da metáfora da engenharia, } \\
\text { e portanto de um designer. O autor argumenta que o trabalho de } \\
\text { engenharia é caracterizado por seguir um planejamento prévio, } \\
\text { dispor de materiais adequados, especialmente moldados para } \\
\text { este projeto, e ainda ter como resultado algo próximo à } \\
\text { perfeição. Demonstrando que a mudança evolutiva por seleção } \\
\text { natural não apresenta nenhuma destas características, Jacob... } \\
\text { propõe que a melhor descrição do processo pelo qual a evolução } \\
\text { caminha é a analogia com o trabalho de um funileiro, o qual usa } \\
\text { objetos disponíveis, muitas vezes sobras de projetos antigos, } \\
\text { para construir novos objetos funcionais de forma criativa, num } \\
\text { processo de bricolagem. Então a questão não é se tem ou não } \\
\text { tem um 'designer', antes disso, é a questão da idéia de design } \\
\text { em si. Ou seja, de se as adaptações podem ser consideradas } \\
\text { um design, algo resultante de um projeto (CS, 11/02/2009). }\end{array}$ \\
\hline
\end{tabular}

continua

${ }^{5}$ Os participantes da comunidade são indicados por códigos de duas ou três letras, correspondentes às iniciais de seus nomes e sobrenomes. 
Participação em uma comunidade virtual ...

Quadro 1. continuação

\begin{tabular}{|c|c|c|}
\hline Categoria & Descrição & Exemplos \\
\hline $\begin{array}{l}\text { Estratégias de ensino e } \\
\text { outros recursos } \\
\text { pedagógicos }\end{array}$ & $\begin{array}{l}\text { Nesta categoria, foram } \\
\text { incluídas mensagens } \\
\text { sobre estratégias de } \\
\text { ensino e recursos } \\
\text { pedagógicos construídos } \\
\text { tanto dentro quanto fora } \\
\text { da comunidade. }\end{array}$ & $\begin{array}{l}\text { Logo que li a reportagem imaginei trabalhar com metabolismo } \\
\text { energético. Os alunos fariam uma leitura prévia do texto, onde } \\
\text { discutiríamos o tema, suas aplicações tanto a nível celular } \\
\text { quanto a nível de contribuições para a sociedade e meio } \\
\text { ambiente. Seria o ponto de partida para os alunos pesquisarem } \\
\text { outros tipos de metabolismo energético e suas respectivas } \\
\text { aplicações que posteriormente seriam discutidas em sala de } \\
\text { aula. Vou elaborar o plano de aula para organizar melhor minhas } \\
\text { idéias (ACS, 31/03/2008). }\end{array}$ \\
\hline $\begin{array}{l}\text { Construção de práticas } \\
\text { pedagógicas e tensões } \\
\text { e conflitos de } \\
\text { professores novatos }\end{array}$ & $\begin{array}{l}\text { Mensagens sobre } \\
\text { tensões e conflitos } \\
\text { experimentados por } \\
\text { professores iniciantes ou } \\
\text { licenciandos em } \\
\text { transição da formação } \\
\text { inicial para a prática, bem } \\
\text { como sobre a construção } \\
\text { de suas práticas } \\
\text { pedagógicas. } \\
\text { Tipicamente, os } \\
\text { licenciandos buscavam } \\
\text { ajuda dos pares, em } \\
\text { particular, dos } \\
\text { professores mais } \\
\text { experientes. }\end{array}$ & $\begin{array}{l}\text { Sou licencianda em biologia... e fui convidada por uma colega } \\
\text { que já leciona há algum tempo, a dar uma aula sobre evolução, } \\
\text { na realidade teorias evolutivas, numa turma de } 7^{a} \text { série de uma } \\
\text { escola privada... me sinto um tanto quanto insegura em abordar } \\
\text { essa temática numa } 7^{a} \text { série, talvez porque não tenha tido } \\
\text { experiências com turmas de } 7^{a} \text { série, ou por não conhecer essa } \\
\text { turma, ou ainda porque trabalhamos com o ensino de evolução } \\
\text { no ensino superior um pouco distante do fundamental... Enfim... } \\
\text { O que os mestres me aconselhariam? que tipo de abordagem? } \\
\text { quais debates podem surgir? como enfrentá-los? (MA, 11/11/ } \\
\text { 2008). }\end{array}$ \\
\hline $\begin{array}{l}\text { Lacuna pesquisa- } \\
\text { prática e a ComPratica }\end{array}$ & $\begin{array}{l}\text { Nesta categoria, reunimos } \\
\text { mensagens que } \\
\text { levantavam a própria } \\
\text { questão da lacuna } \\
\text { pesquisa-prática e } \\
\text { avaliavam a ComPratica } \\
\text { como meio de enfrentá-la. }\end{array}$ & $\begin{array}{l}\text {... acho que podemos construir um movimento muito } \\
\text { interessante de cobrança do ensino médio em relação ao ensino } \\
\text { superior. Vejam que o que se tem falado nesta comunidade gera } \\
\text { uma crítica em relação a lacunas ao ensino superior e lhe impõe } \\
\text { exigências! Acho que precisamos construir esse movimento e } \\
\text { não o inverso, como por exemplo, o vestibular ser um grande } \\
\text { orientador da construção do conhecimento escolar no ensino } \\
\text { médio. Ou melhor, acho que precisamos construir um diálogo, } \\
\text { em que pensemos juntos diretrizes para a construção do } \\
\text { conhecimento biológico nestes dois níveis de ensino (CS, 01/03/ } \\
\text { 2009). }\end{array}$ \\
\hline $\begin{array}{l}\text { Disseminação e } \\
\text { discussão de textos. }\end{array}$ & $\begin{array}{l}\text { Mensagens que } \\
\text { divulgavam textos ou } \\
\text { programas disponíveis } \\
\text { nos meios de } \\
\text { comunicação e em fontes } \\
\text { acadêmicas para os } \\
\text { membros. }\end{array}$ & \\
\hline Anúncios & $\begin{array}{l}\text { Mensagens que } \\
\text { divulgavam cursos e } \\
\text { encontros relacionados à } \\
\text { educação ou à biologia. }\end{array}$ & \\
\hline
\end{tabular}


El-Hani C. N.; Greca, I. M.

Quadro 1. continuação

\begin{tabular}{|l|l|l|}
\hline \multicolumn{1}{|c|}{ Categoria } & \multicolumn{1}{|c|}{ Descrição } & Exemplos \\
\hline $\begin{array}{l}\text { Disseminação de } \\
\text { recursos da internet }\end{array}$ & $\begin{array}{l}\text { Mensagens que } \\
\text { divulgavam tais recursos } \\
\text { no ensino de ciências } \\
\text { para os participantes da } \\
\text { comunidade. }\end{array}$ & \\
\hline $\begin{array}{l}\text { Funcionamento da } \\
\text { comunidade }\end{array}$ & $\begin{array}{l}\text { Mensagens que tratam } \\
\text { de aspectos operacionais } \\
\text { da própria comunidade, } \\
\text { como marcações de } \\
\text { chats, problemas no uso } \\
\text { de algum recurso etc. }\end{array}$ & \\
\hline Outros & $\begin{array}{l}\text { Mensagens que não } \\
\text { puderam ser } \\
\text { classificadas em } \\
\text { qualquer uma das } \\
\text { categorias acima. }\end{array}$ & \\
\hline
\end{tabular}

Um questionário simples foi aplicado aos membros da comunidade, levantando informações sobre: as razões para sua entrada na comunidade, suas expectativas a respeito da mesma, suas avaliações a respeito do modo como ela estava funcionando etc. Informações a este respeito também foram colhidas em reuniões presenciais com membros da comunidade, tanto nas escolas quanto na universidade.

\section{Resultados e discussão}

\section{A participação na comunidade}

A ComPratica foi iniciada em 27/11/2007. Em 10/04/2009, era composta por 64 membros. Quando foi iniciada, em novembro de 2007, a comunidade contava com 7 membros, sendo 5 deles pessoas responsáveis por sua implementação, e a maioria das atividades nesse mês foram relativas a testes do sistema Moodle ${ }^{\mathrm{TM}}$. Entre o final de novembro e meados de dezembro, professores do Ensino Médio e membros do grupo de pesquisa foram entrando na comunidade, que chegou, então, a 28 participantes. Entre maio e agosto de 2008, houve outro aumento do número de membros como consequência de convites feitos a licenciandos de biologia da Universidade Federal da Bahia (UFBA) e da Universidade Estadual de Feira de Santana (UEFS), com a comunidade chegando a 44 membros em agosto. O número de participantes voltou a crescer substancialmente entre janeiro e março de 2009, neste caso, por causa de convites feitos a professores de biologia de todo o país, através de anúncio público sobre a ComPratica na lista de discussão de professores de biologia mantida pela Associação Brasileira de Ensino de Biologia (SBEnBIO, http://www.sbenbio.org.br/). 
Os participantes da ComPratica incluíam, até abril de 2009: 22 professores de biologia do Ensino Médio em serviço (sendo dois deles também estudantes de pós-graduação), dez licenciandos em biologia, 13 professores universitários (sendo 7 deles também estudantes de pós-graduação), 11 estudantes de pós-graduação que não estavam envolvidos com ensino, seis estudantes de graduação e dois membros envolvidos em outras atividades. Todos os estudantes de graduação são de cursos de Biologia, enquanto os estudantes de pós-graduação são de programas de Ensino, Filosofia e História das Ciências, e Ecologia e Biomonitoramento. A presença de uma população com interesses e formações diferentes pode ser considerada um indicador da saúde de uma CoP (SCHLAGER et al., 2002), que é observado na ComPratica.

Quando se observou a distribuição da participação na CoP medida a partir do número de ações registradas nos relatórios do Moodle ${ }^{\mathrm{TM}}$, cinco membros mostraram maior participação, variando de 998 a 2.101 ações da comunidade. Três deles são professores do Ensino Médio (VAP, ACS, DFA) e uma é licencianda de biologia (MAL), mostrando o estímulo da $\mathrm{CoP}$ ao engajamento dos professores.

O caso da licencianda com grau elevado de engajamento ilustra um modo de participação na comunidade que deve ser considerado em maior detalhe. Trata-se de uma participação silenciosa, na qual não vemos a participante escrevendo muitas mensagens ou se envolvendo explicitamente em muitas atividades. Contudo, quando verificamos os registros de sua participação, descobrimos que, de fato, ela entra constantemente na comunidade e examina boa parte das mensagens enviadas.

Este padrão de participação também pode ser verificado, contudo, por outros meios, o que é importante porque, como os membros recebem as mensagens dos fóruns em seus emails pessoais, podem estar participando silenciosamente sem entrar na comunidade e, assim, sem que possamos registrar suas ações. Um destes meios adicionais de verificar a participação silenciosa é o engajamento nos chats, que requer, necessariamente, que o participante entre na comunidade. Por exemplo, um professor do Ensino Médio (AMO) teve apenas cento e cinquenta ações registradas em 11 meses na comunidade, mas participou da maioria dos chats. O mesmo pode ser visto no caso de estudantes de graduação que estavam na comunidade por 17 (INC) e seis meses (KD), ambos com 74 ações registradas, mas que também estiveram bastante envolvidos em chats. Estes são membros que, provavelmente, leem as mensagens em seus emails pessoais e, geralmente, entram na comunidade apenas nas situações em que os conteúdos da discussão não são disponibilizados via email.

Outro indício de participação silenciosa reside no envolvimento nos projetos de pesquisa em construção na comunidade. Por exemplo, uma estudante de pós-graduação (MDG), que participava da comunidade há 17 meses, mas tinha apenas oitenta ações registradas, estava bastante envolvida na investigação de estratégias de ensino com os professores em serviço.

A Figura 1 mostra a distribuição da participação na comunidade de forma a incluir a participação silenciosa de modo mais preciso, considerando envolvimento com atividades que têm papel central na comunidade. Na figura, os membros são distribuídos em círculos, de acordo com os níveis de participação indicados pelas ações registradas no Moodle ${ }^{\mathrm{TM}}$. Se considerarmos apenas esses dados, temos cinco membros $(7,8 \%)$ com o maior nível de participação, como mencionado acima, e 20 membros com níveis intermediários de engajamento $(31,2 \%)$. Contudo, em decorrência da participação silenciosa, devemos considerar o efetivo engajamento dos participantes, tendo em conta outras atividades. Para conseguir esse resultado, incluí- 
mos setas na figura, para mostrar membros que se movem para uma maior participação na comunidade se considerarmos outros dados, além do número de ações registradas no Moodle ${ }^{\mathrm{TM}}$.

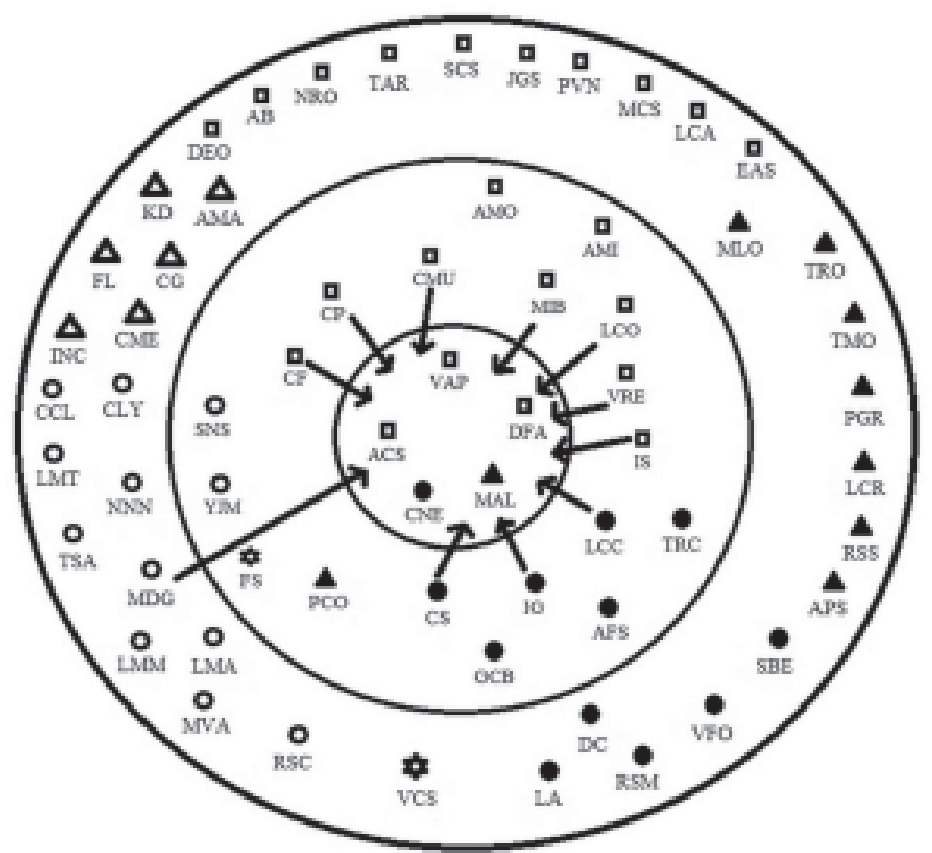

Figura 1. Diagrama mostrando os níveis de participação dos membros na ComPratica. Cada membro é representado por duas ou três iniciais. O círculo mais externo inclui membros com cinco a noventa ações na comunidade. O círculo intermediário mostra membros com noventa e uma a novecentos e noventa ações. No círculo interno, temos membros com mais de novecentos e noventa ações. Professores do Ensino Médio são indicados por quadrados não preenchidos; licenciandos, por triângulos preenchidos; pesquisadores acadêmicos, por círculos preenchidos; estudantes de pós-graduação, por círculos não preenchidos; estudantes de graduação, por triângulos não preenchidos; outros membros, por estrelas. Quando o membro era tanto professor quanto estudante de pós-graduação, nós o representamos como professor. As setas indicam membros com nível mais elevado de participação do que indica o número de ações registradas no Moodle TM (Dados de 10/04/2009). Figura elaborada pelos autores.

As seguintes atividades foram consideradas para identificarmos estes membros: (1) engajamento na construção e implementação de estratégias de ensino sob investigação na comunidade (MDG, CMU, CS, CF, CP, VRE, LCO, LCC, IS); (2) iniciação frequente de fios de discussão (CS, MIB, LCO, LCC, IS); (3) envolvimento na manutenção da operação da comunidade (IG). Se incluirmos estes membros entre aqueles com níveis elevados de participação, chegaremos a 16 membros $(25 \%)$ com forte engajamento na ComPratica e dez membros $(15,6 \%)$ com níveis intermediários de participação (na Figura 1, aqueles que tinham entre noventa e uma e novecentos e noventa ações e não se moviam para uma maior participação, como indicado pelas setas). 
Dezesseis membros da comunidade (25\%) iniciaram fios de discussão com mais de uma mensagem. Entre eles, temos: dez professores do Ensino Médio, um professor universitário, dois professores universitários/estudantes de pós-graduação e três estudantes de pósgraduação. $\mathrm{O}$ fato de que professores do Ensino Médio levantaram a maioria dos tópicos para discussão na comunidade fornece mais uma indicação da relação entre a participação na mesma e o significativo engajamento dos professores. Por sua vez, licenciandos não haviam, até abril de 2009, iniciado fios de discussão, o que pode indicar um maior nível de insegurança ou timidez entre eles.

Podemos caracterizar a participação silenciosa na ComPratica como uma participação periférica legítima (LAVE; WENGER, 1991), entendida como um processo de aprendizagem social no qual participantes gradualmente se engajam em intercâmbios e práticas, movendo-se de uma participação parcial na comunidade para uma participação cada vez mais plena.

A participação desigual dos membros na comunidade não deve ser motivo de preocupação. Diante de tal desigualdade, é natural que desejemos buscar meios de superá-la, particularmente quando lidamos com uma iniciativa pensada como um ambiente de desenvolvimento profissional. Nielsen (2006) aconselha, contudo, que este fenômeno seja aceito como uma característica inevitável de comunidades online e, acrescentaríamos, de qualquer comunidade de seres humanos. A desigualdade de participação sempre estará conosco. A única coisa que se pode tentar é criar condições para uma distribuição mais equitativa da participação.

Sintomaticamente, o fenômeno da desigualdade de participação é muito comum em comunidades virtuais, nas quais a maioria dos membros corresponde a lurkers, i.e., participantes que leem e observam, mas não contribuem. Se considerarmos que $25 \%$ dos membros da ComPratica mostravam níveis elevados de participação, e 15,6\%, níveis intermediários (considerando uma série de ações além da postagem de mensagens na comunidade), veremos que a CoP estava, um ano e meio após sua constituição, muito ativa.

Este é um nível de participação muito maior do que tipicamente observado em comunidades virtuais, nas quais, geralmente, $90 \%$ dos usuários são lurkers (na ComPratica, temos ca. de $61 \%$ de lurkers, considerando apenas a participação via Moodle ${ }^{\mathrm{TM}}$ ) que jamais contribuem com os intercâmbios, e uma pequena minoria dos usuários (ca. 1\%; na Comprática, 7,8\%) responde por quantidade desproporcionalmente grande do conteúdo e de outras atividades (NIELSEN, 2006). Em comunidades virtuais típicas, 9\% dos membros contribuem de modo intermitente (na ComPrática, 31,2\%). Não obstante as desigualdades de participação, estes podem ser considerados níveis satisfatórios de engajamento dos membros.

É verdade que esta é uma comunidade de professores que se engajaram nesta experiência com a expectativa de se desenvolverem profissionalmente e, assim, deveriam tender a ser mais engajados do que o usuário típico de comunidades online. Contudo, se tivermos em conta a falta de tempo e a carga de trabalho dos professores, poderemos concluir que o nível de participação na ComPratica é, de fato, satisfatório. Por fim, não podemos perder de vista que, sendo a ComPratica um ambiente onde os membros trocam materiais, discussões conceituais e sobre a prática, muitos participantes silenciosos provavelmente estão se beneficiando de seu envolvimento na comunidade de uma maneira que não temos como aferir.

Algumas razões para a participação silenciosa foram indicadas pelos próprios professores durante uma reunião presencial, com destaque para o receio em relação a críticas e à falta de um direcionamento das discussões pelo professor universitário que, em sua visão, atuaria 
como coordenador. Quanto à primeira razão, foi tomada a providência de estimular os docentes para que participassem, discutindo-se, em vários momentos, a natureza de uma comunidade de pares, de modo a criar um ambiente mais confortável para a participação. Para que se exponham em interações como aquelas vividas na ComPratica, os professores precisam sentir mais confiança e segurança, bem como assumir a posição de aprendizes por toda a vida, como já vemos em alguns professores da ComPratica. Uma razão para a diferença entre professores que se expõem ou não na comunidade pode residir nos diferentes graus em que exibem um instinto de defesa, resultante do medo de se sentirem vulneráveis diante de estudantes, colegas e pesquisadores (MIRETZKY, 2007).

No caso da segunda razão, a discussão a seu respeito na reunião presencial e em intercâmbios posteriores na comunidade foi fundamental para tornar claro, para os professores, que uma comunidade que envolve pares não tem a mesma natureza de um grupo orientado ou coordenado por algum de seus membros. Assim, não deveria ser esperado que algum membro direcionasse as discussões na comunidade. As direções que porventura fossem seguidas nos intercâmbios seriam aquelas escolhidas pelos seus membros, como uma coletividade, cada qual escolhendo seu caminho para o diálogo. Contudo, é um limite natural de uma comunidade com a natureza da ComPratica que os membros tenham a expectativa da atuação de um coordenador, dada a relação da comunidade com um grupo de pesquisa no qual um pesquisador cumpre tal papel.

Para nós, é evidente que há ainda muito a ser vencido, no que diz respeito seja ao conforto dos professores para se colocarem, seja à expectativa de que os intercâmbios sejam dirigidos por determinados membros da comunidade. Não se pode esperar, sem dúvida, que a intenção e as medidas tomadas para desfazer, na ComPratica, uma hierarquização dos papéis de professores e pesquisadores pudessem lograr resultados, em tão curto termo, na desconstrução de posições sociais em que estes atores vêm se situando durante vários anos. Os professores não se deslocam da posição que geralmente assumem diante da universidade e dos pesquisadores de maneira imediata, ao serem convidados a participar de um ambiente mais colaborativo, como uma comunidade de prática. Eles tendem a se manter na posição hierarquizada em que se encontravam, por uma inércia natural, decorrente dos papéis socialmente construídos que ocupamos. Por sua vez, o modo como nós, pesquisadores, nos colocamos e nos comunicamos na comunidade também tem sua inércia natural, i.e., nós tendemos também a manter a posição que usualmente ocupamos. Desse modo, há uma tendência de que sejam mantidos os papéis usuais de professores e pesquisadores, sendo este um obstáculo à construção de uma prática colaborativa, como pretendemos na ComPratica. O elevado grau de participação na comunidade e o modo como as interações têm ocorrido mostram que foram dados passos efetivos na direção de superar os papéis hierarquizados de pesquisadores e professores, promovendo interações colaborativas nas quais ambos possam se sentir mais confortáveis e seguros. É evidente, contudo, que ainda resta muito a ser caminhado.

Em relação à participação nos fóruns, foram enviadas 488 mensagens (sem contar o fórum de noticias) até abril de 2009, correspondendo a 27 mensagens/mês, em média. Dois fóruns atraíram a maioria da atenção da comunidade: ensino de evolução (165 mensagens) e didática das ciências (238 mensagens). Os fóruns e os chats mais ativos trataram de questões gerais sobre o ensino de ciências. Isso pode decorrer do fato de estarem relacionados a situações mais próximas das práticas cotidianas dos professores e nas quais eles se reconhecem 
mais facilmente como experts. O foco sobre ensino de evolução provavelmente resulta da expectativa dos professores de que os pesquisadores tenham contribuições significativas a dar a respeito deste assunto, pelo fato de o grupo de pesquisa ter a evolução como um dos principais tópicos de interesse e esta ser uma temática que os professores expressam não dominar.

Até abril de 2009, foram realizados seis chats na comunidade, abordando quatro temas diferentes, que tiveram boa participação. Houve dois chats acerca da estratégia de ensino sobre metabolismo energético, que está sendo construída na comunidade a partir da iniciativa de uma professora do Ensino Médio; e dois chats sobre a transição da formação inicial para a prática, um tópico que estimulou bastante discussão na comunidade, em decorrência da interação entre professores em serviço e licenciandos, bastante envolvidos nas tensões e nos conflitos que marcam o começo da carreira docente (e.g., BEJARANO; CARVALHO, 2003). Além dos chats mencionados acima, houve uma discussão sobre a inclusão de estudantes com necessidades especiais nas salas de aula de ciências, provocada pela participação muito ativa de uma professora do Ensino Médio com larga experiência com salas inclusivas. Outro chat realizado abordou uma questão conceitual, resultante de dúvidas expressas no fórum de ensino de evolução, a saber, sobre a distinção entre dois tipos de traços funcionais encontrados em seres vivos, adaptações e exaptações (GOULD; VRBA, 1982). Contudo, a dinâmica do chat se dirigiu para outros assuntos, relacionados às dificuldades enfrentadas por professores de biologia no ensino de evolução.

\section{Análise temática das mensagens dos fóruns}

A maioria das mensagens trata de temas educacionais (134) e de estratégias de ensino, e outros recursos pedagógicos construídos dentro e fora da ComPratica (114). Estas mensagens constituem indícios da construção de um repertório compartilhado de conhecimentos e práticas pela comunidade.

Os participantes discutiram, com bastante profundidade - medida a partir dos conteúdos das mensagens e do número das mesmas trocadas em cada caso -, vários assuntos relacionados à educação, como: a relação entre a natureza abstrata dos conceitos científicos e dificuldades de aprendizagem; a ausência de tratamento histórico das ideias científicas como deficiência dos livros didáticos e da formação de professores; e a organização dos currículos de ciências.

Embora estratégias de ensino e recursos pedagógicos construídos fora da comunidade tenham sido discutidas, a maioria das mensagens a este respeito enfocou propostas construídas de maneira colaborativa na comunidade. Sete estratégias de ensino estão em construção na CoP, em diferentes estágios de desenvolvimento: uma estratégia para ensino de evolução na educação média; uma estratégia de ensino sobre metabolismo energético; uma estratégia de ensino sobre reações químicas, integrada num trabalho interdisciplinar com a estratégia anterior; uma estratégia de ensino usando um jogo de cartas para ensino de biologia celular; trilhas interpretativas como um meio de ensinar ecologia; uma estratégia de ensino usando DVD sobre conceito de vida (ANDRADE, 2009); uma estratégia para ensino de evolução na Educação Superior. Embora não seja o foco do presente trabalho discutir como várias destas estratégias de ensino estão sendo investigadas, visando ao seu aprimoramento e posterior difusão, elas são aqui mencionadas porque fornecem indícios de que um dos objetivos funda- 
mentais da ComPratica está sendo alcançado, a saber, a construção de projetos de pesquisa situados em sala de aula, pelos próprios professores, em colaboração com os membros do grupo de pesquisa. A forma como estas estratégias estão sendo construídas e investigadas pelos próprios professores, a partir de suas problemáticas concretas e em suas salas de aula, com o apoio teórico-metodológico - tanto em termos conceituais como didáticos - do grupo de pesquisa, nos parece um indicativo de que as ações emergentes na comunidade parecem se mover ao longo do contínuo de conhecimentos proposto por McIntyre (2005), rumo a uma diminuição da lacuna pesquisa-prática.

Várias mensagens (61) tratam de diferentes aspectos do funcionamento da própria comunidade. Entre elas, as mais relevantes são as que apresentam propostas dos membros sobre atividades que poderiam ser realizadas na mesma. Uma professora universitária/ estudante de pós-graduação (GCB), por exemplo, propôs que a comunidade poderia ser usada, com maior frequência, para o relato de experiências e divulgação de textos dos membros. Uma professora do Ensino Médio (DFA), por sua vez, provocou os demais membros para que trocassem mais planos de aula, materiais escritos, slides etc.

Desafios do ensino de biologia no nível médio de escolaridade foram discutidos em 58 mensagens. Entre estas mensagens, questões relativas ao ensino de evolução atraíram bastante atenção, sendo abordadas em mensagens de diversos membros.

Embora aspectos conceituais não tenham sido abordados em um grande número de mensagens (33), foi importante observar as questões relevantes e profundas levantadas pelos professores sobre tópicos como: o papel do pensamento evolutivo na biologia, evolução e bricolagem/funilaria, diferenças entre o neodarwinismo e a teoria sintética da evolução, ou a distinção entre adaptação e exaptação. A maioria destas questões foi levantada pelos professores do Ensino Médio.

Nestes dois últimos casos, temos também indicações de que um repertório compartilhado de conhecimentos e práticas está emergindo na ComPratica.

Também foi muito importante ver licenciandos colocando suas dúvidas e preocupações acerca de suas primeiras experiências em sala de aula, assim como as tensões, conflitos e dificuldades que estavam enfrentando na transição da formação inicial para a prática, ainda que somente 27 mensagens tenham abordado este tema até abril de 2009. Estas mensagens podem ter contribuído para o desenvolvimento profissional dos licenciandos, na medida em que eles, de fato, receberam apoio e sugestões, tanto de professores em serviço, quanto de professores universitários engajados na formação de professores.

A comunidade também foi usada, pelos membros, para: divulgar textos e programas encontrados na mídia (22 mensagens), recursos da internet que podiam ser usados por professores de ciências (21), e encontros e cursos sobre educação ou biologia (10). Estas mesmas mensagens são parte da construção de um repertório compartilhado de conhecimentos na ComPratica.

Por fim, vale comentar que a própria questão da lacuna pesquisa-prática e o papel de CoPs como meios de diminuí-la foram discutidos na ComPratica (4 mensagens).

Em vários fios de discussão, vemos um esforço de diversos membros da comunidade para colocarem conhecimentos, sejam teóricos ou práticos, ao alcance uns dos outros, sendo este não somente um alcance físico, mas também conceitual. 


\section{As visões de professores sobre a comunidade}

Nas reuniões presenciais e nos questionários aplicados, foi possível coletar uma série de informações sobre a experiência dos participantes da ComPratica. Numa destas reuniões, por exemplo, ficou evidente que uma das principais motivações dos professores para participarem da ComPratica está relacionada à percepção da dificuldade de retornarem ao espaço da universidade após terem seguido o rumo da docência na Educação Básica. Como declarou uma das professoras: "Depois que sai de lá, para voltar é complicado" (NRO). É unânime, entre os professores, o desejo de voltar a manter algum tipo de vínculo com a universidade, que a ComPratica pôde enfim satisfazer. Muitos almejam e veem como possível o ingresso em cursos de pós-graduação, e/ou a possibilidade de publicarem trabalhos acadêmicos, estando ou não nestes cursos, a partir da experiência na comunidade. No entanto, alguns professores, embora tenham o mesmo desejo, ainda parecem ver essa possibilidade como uma utopia muito difícil de ser alcançada. Outros, ainda, parecem desejar manter o vínculo com a universidade apenas para acessarem informações que possam ser úteis para sua prática.

Quanto aos motivos que os levaram a entrar na ComPratica, os professores também mencionaram: a "vontade de aprender"; a possibilidade de participarem de uma comunidade de discussão pertinente à função docente, permitindo trocar ideias práticas; o fato de a comunidade ser virtual, facilitando a participação nos horários disponíveis; o desejo de encontrarem pares e a oportunidade, ainda rara, de participarem de investigações sobre o ensino de ciências.

Entre as expectativas em relação à participação na comunidade, temos: a de crescer com a experiência, participar de pesquisa, ter mais segurança nas aulas, preparar-se para ingresso na pós-graduação, ampliar as possibilidades de inter-relações entre os conceitos.

Quando lhes foi perguntado se estes motivos foram satisfeitos pela experiência na comunidade, todos responderam que sim: "Com certeza, hoje sou outra professora" (DFA); "depois da ComPrática, de interagir com os colegas, consigo enxergar outras possibilidades dentro do nosso espaço de sala de aula" (VRE).

Também foi evidente o interesse de participar da pesquisa em sala de aula, considerando que isso contribuirá para seu desenvolvimento profissional e sua prática docente. Uma professora destacou a importância de o professor ter um papel de pesquisador nas investigações sobre educação: "O professor passa da condição de informante em pesquisa, para sujeito destas pesquisas" (VRE).

Duas professoras afirmaram perceber uma influência das pesquisas sobre educação em sua prática, "principalmente pelos professores de didáticas, que ao trazer textos de pesquisadores sobre metodologias de ensino, fazia sempre a comparação entre um e outro pesquisador" (DFA). Outros professores não viam esta relação da mesma maneira: "Os trabalhos feitos nas universidades não chegam às salas de aula, em sua maioria" (MIB); "Não, porém percebo uma mudança neste contexto, ainda tímida, mas já existe. Fico feliz" (VRE). As comunidades de práticas foram vistas por eles como uma maneira de aproximar a pesquisa educacional da prática de sala de aula. Como escreveu uma professora, a comunidade está sendo vista como "uma grande oportunidade de incrementar e enriquecer a nossa carreira docente" (VRE).

Entre os aspectos positivos da ComPratica apontados pelos professores, temos, por exemplo: o fato de que as dúvidas são logo esclarecidas pelos colegas; a forma como todos participam, com respeito e carinho; a ausência de cobranças ou julgamentos; a interação sem 
hierarquia; o estímulo à discussão de temas, levando a uma busca de mais informação e à reflexão e mudança das práticas; a troca de experiências entre os professores; a troca de materiais didáticos e outros recursos; a facilidade de acesso às discussões, por ser um ambiente virtual; o fato de que as discussões dizem respeito a necessidades dos professores da Educação Básica; a disponibilização de conhecimentos que podem ser transpostos para a sala de aula.

Os professores percebem, contudo, alguns aspectos a serem aprimorados na comunidade. Uma professora afirmou que seria interessante discutir mais a respeito do planejamento e da organização do trabalho em sala de aula (DFA). De fato, ela própria tomou a atitude de iniciar fio de discussão incitando os colegas a compartilharem seus planejamentos pedagógicos. Alguns professores consideraram importante ampliar o leque de temas trabalhados na comunidade, argumentando que as discussões, muitas vezes, são focadas em evolução. Outro ponto indicado foi a necessidade de mais reuniões presenciais. Por fim, o fato de que algumas discussões que os membros consideram interessantes são iniciadas, mas terminam por serem interrompidas, foi indicado como um aspecto negativo, assim como o fato de que, na maioria das vezes, a participação está restrita a alguns membros da comunidade.

\section{Conclusões}

Concordamos com McIntyre (2005) que não há soluções simples para diminuir a lacuna pesquisa-prática. Por isso, pensamos que somente podemos diminuir a distância entre nossa pesquisa e o ensino em sala de aula engajando-nos em interação e diálogo de longo termo com professores em serviço e em formação. Nossa abordagem para promover esta interação duradoura foi implementar uma comunidade virtual de prática, a ComPratica. Os primeiros resultados obtidos, ao longo de um ano e meio, indicam que esta CoP pode ser, de fato, uma ferramenta valiosa para aproximar a pesquisa da prática, e vice-versa. Em seu interior, tem sido estabelecida uma atmosfera colaborativa, na qual professores e pesquisadores constituem uma rede que começa a colocar em questão os próprios papéis que uns costumam assumir em relação aos outros, que são, sem dúvida, parte das causas da lacuna pesquisaprática. Ela tem permitido integrar uma parcela importante dos atores envolvidos nos ambientes de formação de professores, na pesquisa educacional e na prática pedagógica, contribuindo para o aprimoramento do ensino de ciências, a preparação de futuros professores e o desenvolvimento profissional docente, e, ao mesmo tempo, para a aproximação da pesquisa educacional e da prática docente.

Em 2003, Gordon comentava que os resultados de pesquisa sobre a efetividade das comunidades virtuais de prática para a melhoria das práticas docentes eram ainda anedóticos, destacando a necessidade de dados mais concretos. Consideramos que os resultados apresentados neste trabalho, relativos à participação dos membros da comunidade, avançam nessa direção, sobretudo no que tange ao desenvolvimento profissional docente. A seguir, destacamos alguns aspectos relativos aos nossos achados que consideramos relevantes.

Em primeiro lugar, a participação espontânea dos professores na comunidade é alta, se comparada com os dados da literatura. Por outra parte, os resultados que apresentamos parecem mostrar que, embora ainda em uma fase inicial de desenvolvimento, a ComPratica possui as mesmas características destacadas por Dalgarno e Colgan (2007) na CoP Connect-me. 
A ComPratica tem se mostrado um espaço propício para o compartilhamento de recursos e experiências pessoais e para o acesso a produções textuais de qualidade - fornecidas tanto pelos pesquisadores associados ao projeto quanto pelos professores participantes. Em seu trabalho, Dalgarno e Colgan salientam a necessidade de mais pesquisas para se conhecer o papel que a colaboração desempenha no suporte às práticas de sala de aula dos professores. $\mathrm{Na}$ ComPratica, as práticas colaborativas se tornam evidentes na emergência de projetos didáticos concretos, que têm sido desenvolvidos nas salas de aula dos professores participantes nos últimos três anos. Estes projetos, como já indicamos, têm surgido a partir de colocações dos professores participantes e têm sido coconstruídos pela comunidade. Assim, a ComPratica se mostra efetivamente uma CoP, no sentido de que nela se resolvem problemas emergentes das práticas concretas de sala de aula em conjunto.

Hiebert, Gallimore e Stigler (2002) consideram que um dos grandes desafios para o aprimoramento profissional de professores é o estabelecimento de uma base de conhecimentos para a profissão docente que possa crescer e se aprimorar, partindo do conhecimento dos praticantes - ou seja, do tipo de conhecimento que os praticantes geram através da participação ativa e da reflexão sobre sua prática -, para a incorporação dos resultados da pesquisa educacional, desde que relevantes para a prática de sala de aula. A ComPratica, implementada a partir de um grupo de pesquisa em ensino de ciências, mas caminhando para crescente autonomia, pretende ser uma via para superar a lacuna pesquisa-prática, partindo justamente do conhecimento e das necessidades de professores de biologia, passando pela reflexão sobre suas práticas, para gerar, conjuntamente, propostas úteis para a sala de aula. Para conseguir isto, consideramos fundamental uma estrutura horizontal, na qual o conhecimento e a participação de todos os membros sejam considerados importantes e valorizados. Os questionários respondidos pelos professores, assim como as dinâmicas observadas na ComPratica, sugerem que a CoP está desenvolvendo esta estrutura horizontal, apesar das dificuldades naturais de deslocar professores e pesquisadores de suas posições usuais. Acreditamos que estes dois elementos, a emergência de projetos colaborativos e a horizontalidade da sua estrutura, certamente inter-relacionados, constituem novidades na literatura sobre CoPs e desenvolvimento profissional de docentes.

Apesar dos resultados positivos que obtivemos, a ComPratica ainda é uma comunidade bastante nova. Contudo, há razões para se ter confiança em seu futuro, como mostram o elevado nível de participação alcançado; a diversidade de temas discutidos em seu interior; e o desenvolvimento de projetos situados na sala de aula, focados, sobretudo, em questões levantadas pelos professores. De qualquer modo, são necessárias ações para consolidar a comunidade, como, por exemplo, a abertura das discussões nos fóruns e chats para outros temas, evitando-se o foco excessivo no ensino de evolução, a realização de mais chats e reuniões presenciais, e o foco crescente sobre ações concretas.

Apesar de nosso otimismo com a ComPratica, não pretendemos dizer que construir comunidades de prática (virtuais ou presenciais) seja a solução para a lacuna pesquisa-prática. Este é um problema multifacetado e sensível ao contexto, de modo que duvidamos que uma panacéia generalizada qualquer possa ser a resposta. Apenas consideramos que, no contexto em que trabalhamos, e no qual atuam os professores com os quais interagimos, a ComPratica tem se mostrado uma ferramenta valiosa para a interação produtiva entre seus participantes. Ela tem propiciado condições para a construção de uma pesquisa colaborativa entre professo- 
res e pesquisadores, mais próxima das necessidades, dificuldades, possibilidades e limites das salas de aula, mas, ao mesmo tempo, indo além de uma coleção de protocolos para o trabalho pedagógico, de qualquer conjunto de receitas para o ensino.

\section{Agradecimentos}

Os autores agradecem ao Conselho Nacional de Desenvolvimento Científico e Tecnológico (CNPQ), à Fundação de Amparo à Pesquisa do Estado da Bahia (FAPESB) e ao Instituto Anísio Teixeira (IAT), pelo financiamento de bolsas e das pesquisas das quais este artigo resulta. Agradecemos, também, aos professores do Ensino Médio e licenciandos, que têm compartilhado conosco esta experiência, com tanto entusiasmo, nos últimos quatro anos; a Claudia Sepulveda, Thiago Serravalle de Sá, Maria Daniela Martins Guimarães, Mariangela Almeida, Rosiléia Oliveira e Izaura Cruz, pela grande ajuda na condução dos trabalhos com os professores; e à equipe Moodle/UFBA, por todo o apoio que nos tem concedido.

\section{Referências}

ALLEN, T. H. F.; HOEKSTRA, T. W. Toward a unified ecology. New York: Columbia University Press, 1992.

BARAB, S. A.; DUFFY, T. M. From practice fields to communities of practice. In: JONASSEN, D.; LANDS, S. (Eds.). Theoretical foundations of learning environments. Mahwah: Erlbaum, 2000. p. 29-56.

BARAB, S. A.; BARNETT, M.; SQUIRE, K. Developing an empirical account of a community of practice: characterizing the essential tensions. Journal of the Learning Sciences, Mahwah, v. 11, n. 4, p. 489-542, 2002.

BEJARANO, N. R. R.; CARVALHO, A. M. P. Professor de ciências novato, suas crenças e conflitos. Investigações em Ensino de Ciências, Porto Alegre, v. 8, n. 3, p. 257-280, 2003. Disponível em: < http://www.if.ufrgs.br/ienci/artigos/Artigo_ID107/ v8_n3_a2003.pdf>. Acesso em: 28 jun. 2011.

BERO, L. A. et al. Closing the gap between research and practice: an overview of systematic reviews of interventions to promote the implementation of research findings.

British Medical Journal, London, v. 317, n. 7156, p. 465-468, 1998.

BROEKKAMP, H.; VAN HOUT-WOLTERS, B. The gap between educational research and practice: a literature review, symposium and questionnaire. Educational Research and Evaluation, Abingdon, v. 13, n. 3, p. 203-220, 2007. 
Participação em uma comunidade virtual ...

BROWN, S. How can research inform ideas of good practice in teaching?: the contributions of some official initiatives in the UK. Cambridge Journal of Education, Cambridge, UK, v. 35 , n. 3 , p. $383-406,2005$.

BROWN, J. S.; DUGUID, P. The social life of information. Cambridge: Harvard Business School Press, 2000.

DALGARNO, N.; COLGAN, L. Supporting novice elementary mathematics teachers' induction in professional communities and providing innovative forms of pedagogical content knowledge development through information and communication technology. Teaching and Teacher Education, New York, v. 23, n. 7, p. 1051-1065, 2007.

EL-HANI, C. N.; GRECA, I. M. Bridging the research-practice gap in science education with a virtual community of practice (ComPratica). In: IOSTE SYMPOSIUM, 14., 2010, Bled, Slovenia. Proceedings... Disponível em: <http:// files.ecetera.si/IOSTE/188.pdf>. Acesso em: 28 jun. 2011.

GARCÍA GANDÍA, J.; GRECA, I. M.; MENESES VILLAGRÁ, J. Las comunidades virtuales de práctica para el desarrollo profesional docente en Enseñanza de las Ciencias. Enseñanza de las Ciencias: Revista de Investigación y Experiencias Didácticas, Barcelona, v. 23, n.extra, p. 1-5, 2005.

GORDON, D. T. Linking teachers with technology: online courses and communities provide ways of delivering professional development and support. Harvard Education Letter, Cambridge, US, v. 19, n. 6, p. 1-4, 2003. Disponível em: <http://www.hepg.org/ hel/article/256>. Acesso em: 28 jun. 2011.

GOULD, S.; VRBA, E. S. Exaptation - a missing term in the science of form.

Paleobiology, Washington, v. 8, n. 1, p. 4-15, 1982.

GRECA, I. M.; GONZÁLEZ, E. Comunidades de aprendizaje en desarrollo sustentable. In: ENCUENTRO DE DIDÁCTICA DE LAS CIENCIAS EXPERIMENTALES, 20., 2002. Actas... La Laguna: Universidad de La Laguna, 2002. p. 231-238.

HARGREAVES, D. H. The knowledge-creating school. British Journal of Educational Studies, Abingdon, v. 47, n. 2, p. 122-144, 1999.

HIEBERT, J.; GALLIMORE, R.; STIGLER, J. W. A knowledge base for teaching profession: what would it look like and how can we get one? Educational Researcher, Thousand Oaks, v. 31, n. 5, p. 3-15, 2002.

KENNEDY, M. M. The connection between research and practice. Educational Researcher, Thousand Oaks, v. 26, n. 7, p. 4-12, 1997.

KIRK, J.; MILLER, M. L. Reliability and validity in qualitative research. Newbury Park: Sage, 1986.

LAVE, J.; WENGER, E. Situated learning: legitimate peripheral practice. New York: Cambridge University Press, 1991. 
El-Hani C. N.; Greca, I. M.

LIEBERMAN, A. Creating intentional learning communities. Educational Leadership, Sussex, v. 54, n. 3, p. 51-55, 1996.

LÜDKE, M. O professor pesquisador e a relação entre teoria e prática. In: LÜDKE, M. et al. (Orgs.). O professor e a pesquisa. Campinas: Papirus. 2001. p. 25-34.

MCINTYRE, D. Bridging the gap between research and practice. Cambridge Journal of Education, Cambridge, UK, v. 35, n. 3, p. 357-382, 2005.

MIRETZKY, D. A view of research from practice: voices of teachers. Theory into Practice, Philadelphia, v. 46, n. 4, p. 272-280, 2007.

MYERS, M. F. Bridging the gap between research and practice: the Natural Hazards Research and Applications Information Center. International Journal of Mass Emergencies and Disasters, Stillwater, v. 11, n. 1, p. 41-54, 1993.

NIELSEN, J. Participation inequality: encouraging more users to contribute. Alertbox, Fremont, Oct. 9, 2006. Disponível em: < http://www.useit.com/alertbox/ participation_inequality.html>. Acesso em: 28 jun. 2011.

PEKAREK, R.; KROCKOVER, G.; SHEPARDSON, D. The research/practice gap in science education. Journal of Research in Science Teaching, Hoboken, v. 33, n. 2, p. 111-113, 1996.

PENA, F. L. A.; RIBEIRO FILHO, A. Relação entre a pesquisa em ensino de física e a prática docente: dificuldades assinaladas pela literatura nacional da área. Cadernos Brasileiros de Ensino de Física, Florianópolis, v. 25, n. 3, p. 424-438, 2008.

QUEM foi que disse? Sobre a vida e o viver. Produção e coordenação de Luiz Antonio Botelho Andrade. Rio de Janeiro: UFF, 2009. 1 DVD.

RÉNYI, J. Teachers take charge of their learning: transforming professional development for student success [and] executive summary. Washington: National Foundation for the Improvement of Education, 1996. (Report). Disponível em: <http://www.eric.ed.gov/PDFS/ED401251.pdf>. Acesso em: 28 jun. 2011.

SCHLAGER, M.S.; FUSCO, J. Teacher professional technology, and communities of practice: are we putting the cart before the horse? In: BARAB, S.; KLING, R.; GRAY, J. (Eds.). Designing virtual communities in the service of learning. Cambridge: Cambridge University Press, 2004. p. 235-256.

SCHLAGER, M. S.; FUSCO, J.; SCHANK, P. Evolution of an on-line education community of practice. In: RENNINGER, K.A.; SHUMAR, W. (Eds.). Building virtual communities: learning and change in cyberspace. Cambridge: Cambridge University Press, 2002. p. 129-158.

SCHÖN, D. The reflective practitioner: how professionals think in action. New York: Basic Books, 1983. 
Participação em uma comunidade virtual ...

SCHOONMAKER, F. One size doesn't fit all: reopening discussion of the research-practice connection. Theory into Practice, Philadelphia, v. 46, n. 4, p. 264-271, 2007.

SHORT, D. C. Closing the gap between research and practice in HRD. Human Resource Development Quarterly, v. 17, n. 3, p. 343-350, 2006.

TOULMIN, S. Regreso a la razón. Barcelona: Península, 2001.

VANDERLINDE, R.; VAN BRAAK, J. The gap between educational research and practice: views of teachers, school leaders, intermediaries and researchers. British Educational Research Journal, Hoboken, v. 36, n. 2, p. 299-316, 2010.

WENGER, E. Communities of practice: learning, meaning, and identity. New York: Cambridge University Press, 1998.

WISKER, G., ROBINSON, G.; SHACHAM, M. Postgraduate research success: communities of practice involving cohorts, guardian supervisors and online communities. Innovations in Education and Teaching International, Abingdon, v. 44, n. 3, p. 301-320, 2007. 